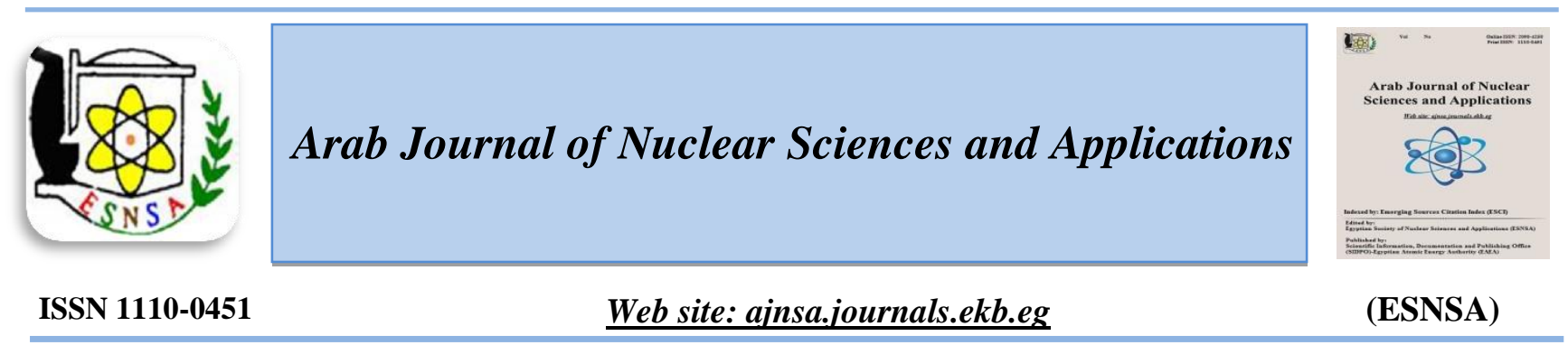

\title{
Effect of Organic Manure Application on Neutron Moisture Meter Calibration Curve of Sand Soil
}

\author{
KH.M ${ }^{(1)}$ and Yousef and M.A. Salama ${ }^{(2)}$ \\ ${ }^{(1)}$ Soils and Water Research Department, Nuclear Research Center, \\ ${ }^{(2)}$ Atomic Energy Authority, Cairo, Egypt
}

\begin{abstract}
Neutron moisture meter (NMM) calibration accuracy and precision must be performed to obtain reliable results. The aim of this study is to investigate the effect of applied organic manure on neutron moisture meter calibration curve of sandy soil. The experiment was carried out at the farm of Soils and Water Department, Atomic Energy Authority. Two rates of organic manure were added (48 and $71.5 \mathrm{~m}^{3} / \mathrm{ha}$ ) including untreated control to surface sand soil at depth $20 \mathrm{~cm}$. Neutron moisture meter calibration curve for 30 and $50 \mathrm{~cm}$ depth were done, the results showed that a $30 \mathrm{~cm}$ depth the neutron calibration curves for three treatments have approximately the same slope, and there is differences in the intercept which were $1.131,1.298$ and 1.978 for rate 2 , rate 1 and the control, respectively. The values of the volumetric soil water content versus count ration presented in Tables $(2$ and 3$)$ showed that, at the same count ratio, the values of water content decrease with increasing the rate of the organic matter in the case of $30 \mathrm{~cm}$ depth. As for $50 \mathrm{~cm}$ depth, the values of soil water content were approximately the same at each count.
\end{abstract}

Keywords: Organic matter; Neutron probe; Calibration; Sand soil

\section{Introduction}

Efficient irrigation requires a systematic program. Such a program answers questions such as when to irrigate, how much water to apply during irrigation and how best to apply the water (application rate, weather.... etc.). The main component of the water budget for water management is the soil water content [1]. It is very difficult to be measured in the field.

Evett et al. [2] reported that accurate volumetric soil water content $\left(\theta_{\mathrm{v}}\right)$ estimation is required to determine crop water use, water use efficiency and irrigation efficiency. Schmugge et al. [3] explained that soil moisture was measured indirectly by NMM from estimating the thermal or slow neutrons density from a radioactive source. NMM must be calibrated to measure the actual soil moisture content to a particular soil type and depth. NMM is considered the most accurate method for measuring soil water content in the field when properly calibrated, and it is the only indirect method capable of providing accurate soil water balance data for crop water use, water use efficiency, irrigation efficiency and irrigation water use efficiency, with a minimum number of access tubes [4]. NMM calibration involves quantifying the relationship between the neutron probe output and soil water content $\theta$. The intercept and slope of the NMM calibration curve varies from a soil to a soil and from a probe to a probe, the intercept value should not equal zero or be close to it.

Koksal et al. [5] reported that NMM calibration accuracy is critical to obtain reliable results, and a linear regression analysis of soil moisture content against NMM count ratio data is the most common

Corresponding author:mnsalama@yahoo.com

DOI: 10.21608/ajnsa.2018.2844.1055

(C) Scientific Information, Documentation and Publishing Office (SIDPO)-EAEA 
method of calibration. Neutron moisture meter calibration curves are the relationships between counts per minute and the percentage of the volumetric soil water content. This is a linear relationship through the common range of soil moisture [6]. Neutron energy is efficiently reduced by the hydrogen atom, hence soil water is used as a good neutron moderator because of its hydrogen content, With the exception of organic matter, which may gradually change with time, soil materials containing hydrogen remain constant and are taken into account during calibration [7].

\section{Materials and Methods}

This study was carried out at the farm of Soils and Water Department, Nuclear Research Center, Atomic Energy Authority. Two rates of organic manure were thoroughly mixed with surface sand soil $(0-20 \mathrm{~cm})$ at the rate of 0,48 and $71.5 \mathrm{~m} 3 / \mathrm{ha}$ to sand soil at the first $20 \mathrm{~cm}$ depth beside the control. The soil was classified as sand soil $(97.8$ sand, 1.4 silt and 0.8 clay). The experimental plot area was $9 \mathrm{~m} 2(3 \times 3)$ each treatment was conducted in triplicate. An access tube of neutron scattering meter was installed in the center of each plot to detect the changes in count ratio at the two depths $(30$ and $50 \mathrm{~cm})$ under the study. Three readings using neutron moisture meter $\mathrm{CPN}$, $50 \mathrm{mCi}$. (503 DR hydroprobe) were taken at the two depths.

Soil moisture content (mass basis) determined by taking a disturbed soil samples from the out of the two measurement depths of the Neutron moisture meter probe, using a soil auger. Wet mass values were measured, in order to define dry mass. Samples were dried in an oven at $105^{\circ} \mathrm{C}$ until constant weight. The volumetric water content $(\theta \mathrm{v})$ values of each sample were calculated by multiplying the mass basis water content by the ratio between soil bulk density of certain soil layer and water density. Standard counts were taken with the neutron moisture meter above the soil surface by putting the device on the original box. Count ratios were calculated by dividing each count by the standard count [8]. Calibration curves were carried out through determination of the linear relationship between measured $\theta \mathrm{v}$ and neutron count ratios for each $30 \mathrm{~cm}$ and $50 \mathrm{~cm}$ soil depths. Thus, three different regression equations were obtained to each depth. For determination of soil bulk density of two soil layer, undisturbed core samples of $53 \mathrm{~mm}$ diameter and $50 \mathrm{~mm}$ length, were used. According to the method described by Blake et al., [9] the bulk density values were 1.78 to $1.77 \mathrm{~g} \mathrm{~cm}^{-3}$ to the two depths respectively.

\section{Results and Discussion}

The positive correlations were obtained from the relation between neutron count ratio and volumetric soil water content for the three treatments (control, rate1 and rate2) as shown in Table (1) and illustrated in Figs. (1 and 2). At $30 \mathrm{~cm}$ depth, increasing the organic matter had markedly decreased the liner relationship intercept, where they were $1.978,1.298$ and 1.1309 for the control, rate1 and rate2, respectively; however the slops were approximately the same for the three treatments which were 13.643, 13.7059 and 13.699. At $50 \mathrm{~cm}$ depth, the calibration curves were approximately the same for the slope and intercept Table (1) and Figure (2). This could be attributed to the effect of the hydrogen atom in the organic matter on the neutron moderation. An IAEA publication [10] reported that neutron probe emits approximately a spherical cloud of slow neutrons, called the sphere of influence or the sphere of importance. The radius of slow neutrons is a function of the soil-water content (i.e. the hydrogen content). In pure water, this radius is approximately 5 to $8 \mathrm{~cm}$, in very dry soils, it may reach $20 \mathrm{~cm}$ or more. This radius depends on the soil water content. Kristensen [11] presented an equation for predicting the sphere of influence as follows: $(\mathrm{R}=100 /(1.4+0.1 \mathrm{~W})$ where $\mathrm{R}$ is the radius $(\mathrm{cm})$ and $\mathrm{W}$ is the volumetric water content (\%). Hence the sphere's radius is a function of moisture content, decreasing as (W) increases. So, in $50 \mathrm{~cm}$ depth both of the intercept and slope are approximately the same, this is because the organic matter is far from radius of scattered neutrons, so there is no effect of organic matter on neutron count ratio.

The values of volumetric soil water content versus count ration presented in Tables (2 and 3) show that at the same count ratio, the values of water content decrease with increasing the rate of the organic matter in the case of $30 \mathrm{~cm}$ depth. As for $50 \mathrm{~cm}$ depth, the values of soil water content were approximately the same at each count 
Table (1): Neutron moisture calibration curves for two soil depths under two organic matter application rates

Soil depth Neutron moisture calibration equations

\begin{tabular}{cccc}
$(\mathrm{cm})$ & Control & Rate 1 & Rate 2 \\
\hline $0-30$ & $\theta_{\mathrm{v}}=13.643$ C.R-1.978 & $\theta_{\mathrm{v}}=13.7059$ C.R-1.298 & $\theta_{\mathrm{v}}=13.699$ C.R-1.1309 \\
$30-50$ & $\theta_{\mathrm{v}}=15.321$ C.R-2.9727 & $\theta_{\mathrm{v}}=15.2800$ C.R-3.0124 & $\theta_{\mathrm{v}}=15.267$ C.R-3.8689
\end{tabular}

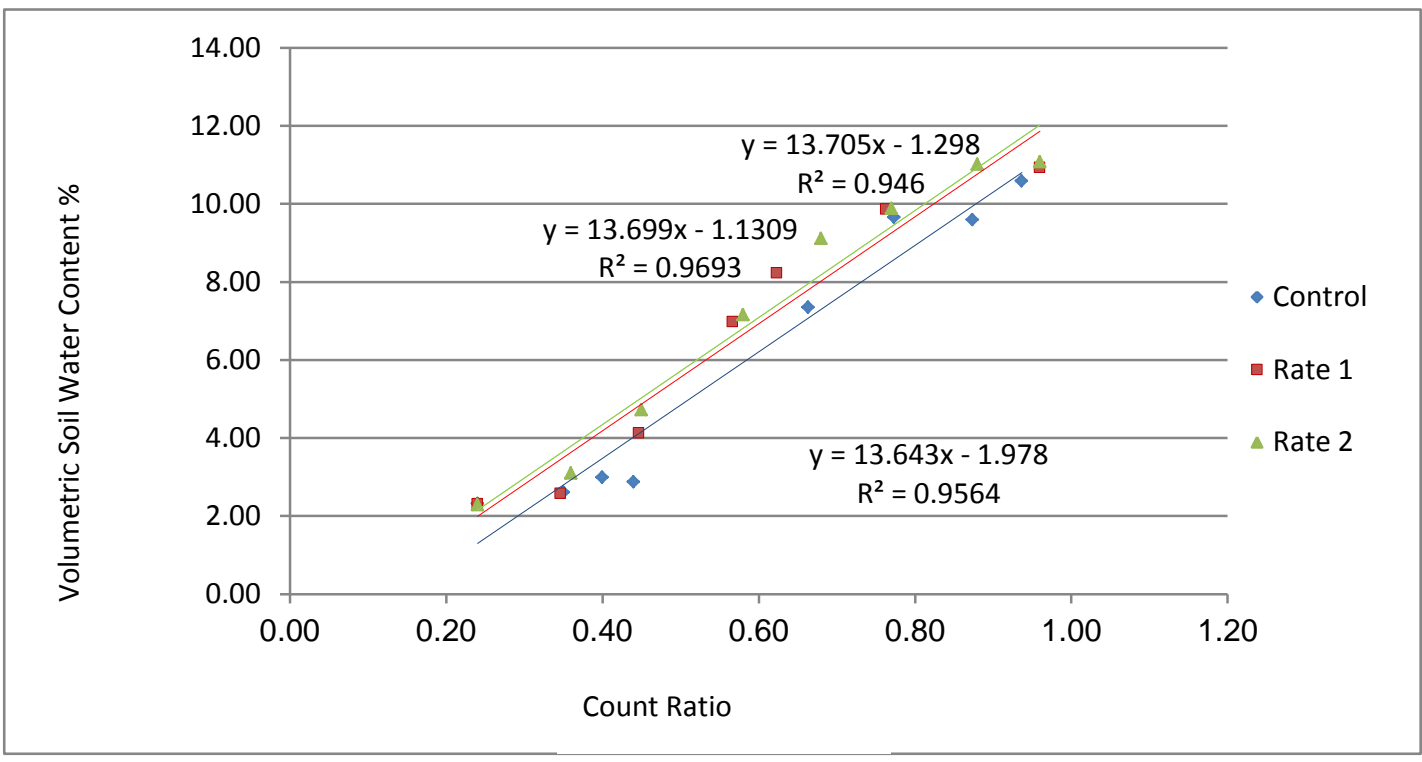

Figure (1): Effect of organic matter addition on neutron probe calibration curve form $0-30 \mathrm{~cm}$ soil depth

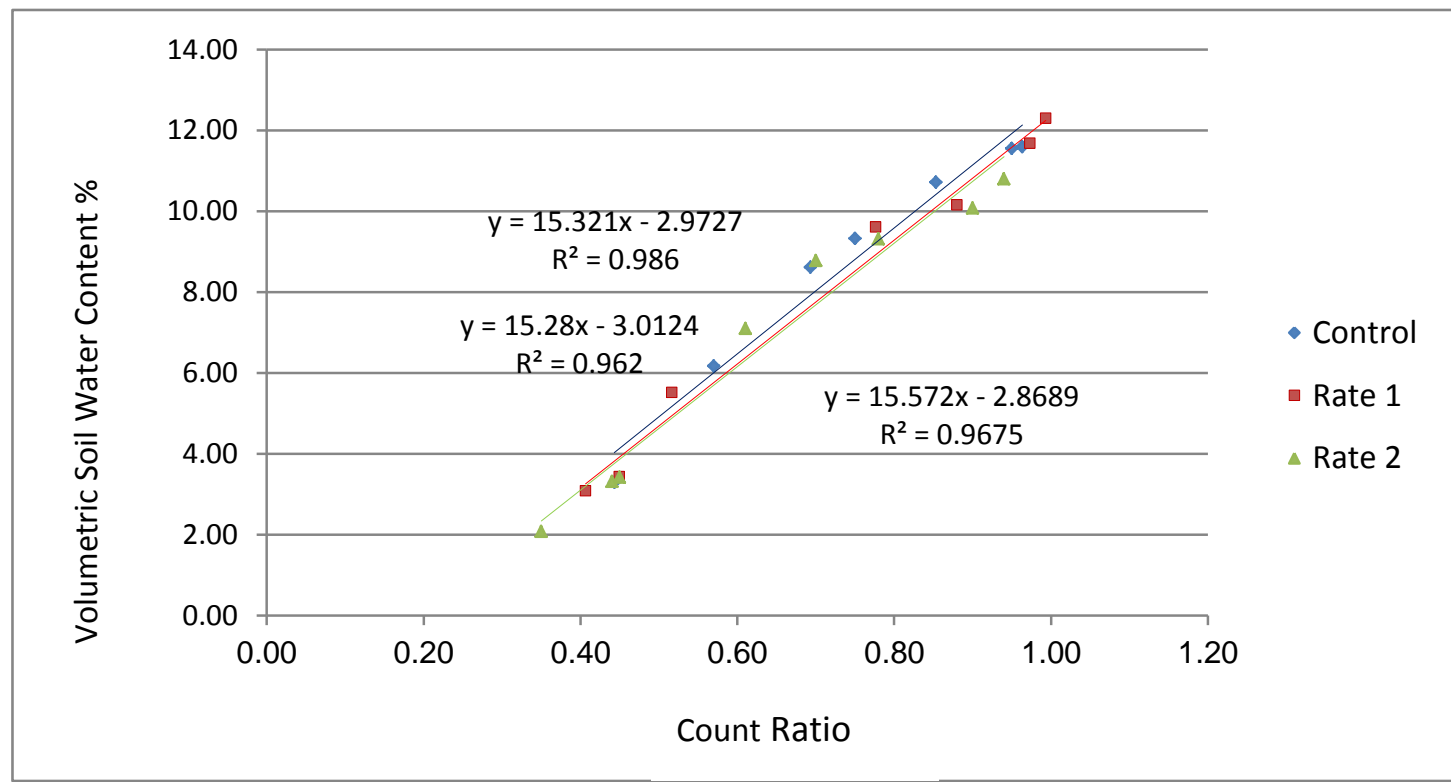

Figure (2): Effect of organic matter addition on neutron probe calibration curve form $30-50 \mathrm{~cm}$ soil depth 
Table (2): Volumetric soil water content with a different organic matter form $0-30 \mathrm{~cm}$ soil depth

\begin{tabular}{cccc}
\hline Count Ratio & \multicolumn{3}{c}{ Volumetric Soil Water Content \% } \\
& Control & Rate 1 & Rate 2 \\
\hline 0.3 & 2.8420 & 2.6310 & 1.6490 \\
0.4 & 4.2515 & 4.0370 & 3.0670 \\
0.5 & 5.6610 & 5.4430 & 4.4860 \\
0.6 & 7.7050 & 6.8490 & 5.9040 \\
0.7 & 8.4800 & 8.2540 & 7.3220 \\
0.8 & 9.8895 & 9.6600 & 8.7400 \\
0.9 & 11.290 & 11.066 & 10.158 \\
1.0 & 12.709 & 12.472 & 11.576 \\
\hline
\end{tabular}

Table (3): Volumetric soil water content with a different organic matter for $30-50 \mathrm{~cm}$ soil depth

\begin{tabular}{cccc}
\hline Count Ratio & \multicolumn{3}{c}{ Volumetric Soil Water Content \% } \\
& Control & Rate 1 & Rate 2 \\
\hline 0.3 & 1.8030 & 1.6240 & 1.5720 \\
0.4 & 3.3600 & 3.1560 & 3.1000 \\
0.5 & 4.9170 & 4.6880 & 4.6280 \\
0.6 & 6.4730 & 6.2200 & 6.1560 \\
0.7 & 8.0320 & 7.7520 & 7.6840 \\
0.8 & 9.5890 & 9.2840 & 9.2120 \\
0.9 & 11.146 & 10.816 & 10.740 \\
1.0 & 12.703 & 12.348 & 12.268 \\
\hline
\end{tabular}

\section{Conclusion}

The presence of a hydrogen atom in the organic matter has an effect on the calibration curve of neutron moisture meter, through moderation process for fast neutron. The present study explained that differences occurred in the intercept as a result of organic matter addition, and same slope for $30 \mathrm{~cm}$ soil depth. On the other hand, the soil of $50 \mathrm{~cm}$ depth was not affected by the organic matter addition.

\section{References}

1-Robinson, D.A., Campbell, C.S., Hopmans, J.W., Hornbuckle, B.K., Jones, S.B., Knight, R., Ogden, F., Selker, J. and Wendroth, O. (2008) Soil moisture measurement for ecological and hydrological watershed-scale observatories: A review. Vadose Zone J., (7), 358-389.

2-Evett, S.R., Tolk, J.A. and Howell, T.A. (2006) Soil profile water content determination: Sensor accuracy, axial response, calibration, temperature dependence and precision. Vadose Zone J., (5), 894-907.

3-Schmugge, T.J., Jackson, T.J. and McKim, H.L. (1980) Survey of soil moisture determination. Water Resources Research, (16), 961-979.

4-IAEA (2008) Neutron and gamma probe: Their use in agronomy. Training Course Series 16, Vienna.

5-Koksal, E.S., Cemek, B., Artık, C., Temizel, K.E. and Taşan, M. (2010) A new approach for neutron moisture meter calibration: artificial neural network. Irrigation Science, (29), 369-377.

6-Merriam, R.A. and Knoerr, K.R. (1961) Counting times required with neutron soil moisture probes. Soil Sci., (92), 394-395.

7-IAEA (2003) Field estimation of soil water content, a practical guide to methods, Instrumentation and Sensor Technology. Training Course Series 30, Vienna.

8-Hillel, D. (1980) Introduction to Soil Physics. Academic Press, New York. ISBN 0-12-348520-7.

9-Blake, G.R. and Hartge K.H. (1986) Bulk density. In: A. Klute. Methods of soil analysis. Part 1. 2nd ed. Agron, Monogr. 9. Madison, WI: ASA and SSSA, Madison, pp. 363-375.

10-IAEA (1970) Neutron moisture gauges, IAEA, Vienna.

11-Kristensen, K.J. (1973) Depth intervals and topsoil moisture measurement with the neutron depth probe. Nordic Hydrol., (4),77-85. 